Article

\title{
Phenacylation of 6-Methyl-Beta-Nitropyridin-2-Ones and Further Heterocyclization of Products
}

\author{
Eugene V. Babaev * ${ }^{D}$ and Victor B. Rybakov $(D)$
}

Chemistry department, Moscow State University, Leninskie gory, 1 str.3, Moscow 119899, Russia; rybakov20021@yandex.ru

* Correspondence: babaev@org.chem.msu.ru; Tel.: +7-985-997-94-75

Academic Editor: Nagatoshi Nishiwaki

Received: 2 March 2020; Accepted: 4 April 2020; Published: 7 April 2020

\begin{abstract}
Reaction between the derivatives of 6-methyl-beta-nitropyridin-2-one and phenacyl bromides was studied, and the yields observed were extremely low. The pyridones were converted via chloropyridines to methoxyderivatives, which were $N$-phenacylated. $\mathrm{N}$-Phenacyl derivatives of 4,6-dimethyl-5-nitropyridin-2-one under the action of base gave 5-hydroxy-8-nitroindolizine and under acidic conditions gave 5-methyl-6-nitrooxazole[3,2-a]pyridinium salt, which underwent recycization with MeONa to 5-methoxy-8-nitroindolizine.
\end{abstract}

Keywords: Phenacylation of beta-nitropyridin-2-ones; 8-nitro-5-RO-indolizines; oxazole-pyrrole ring transformation

\section{Introduction}

Indolizine is an important member of the class of heterocyclic compounds, and many alkaloids have in their structures a saturated or aromatic indolizine moiety. While the chemistry of indolizines has been widely investigated [1], the chemistry of 5-substituted indolizines (A, Scheme 1) remains very poor because there are only a few reliable ways for their synthesis. Thus, there are examples of electrophilic substitution of indolizines lithiated at C-5 [2-4] and $\mathrm{S}_{\mathrm{N}} \mathrm{H}$ reaction of 8-nitroindolizines at this position [5]. The standard Tchitchibabin reaction requires interaction of 6-substituted 2-picolines and alpha-bromoketones; by steric reasons, however, this reaction is almost impossible for 5-X-indolizines. Exceptional case is the cyclization of pyridones B (Scheme 1) bearing acceptor (EWG) group at beta-position [6,7]. The last methodology developed in our laboratory is the recyclization of 5-methyl substituted oxazolo[3,2-a]pyridinium salts $\mathbf{C}$ via pyridinium betaine $\mathbf{D}$ (Scheme 1), which leads to 5 -substituted indolizines [8,9]. In turn, the salts $\mathbf{C}$ are available via acidic cyclization of pyridones $\mathbf{B}$ [10]:

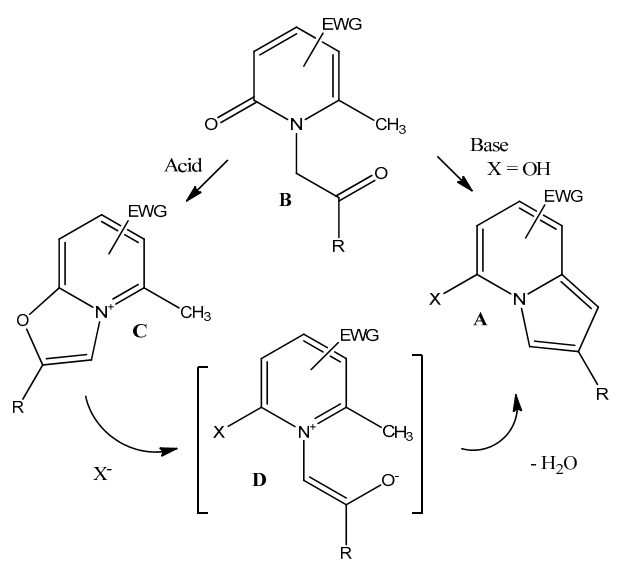

Scheme 1. Possible transformations of N-(2-oxoethyl)-6-methylpyridin-2-ones. 
The aim of this work was to test the validity of Scheme 1 for the case of more powerful acceptor a nitro group $\left(\mathrm{EWG}=\mathrm{NO}_{2}\right.$ ) by choosing the 6-methyl-beta-nitropyridin-2-ones as the parent compounds. Obtained by such strategy 6- or 8-nitroindolizines with the substituent $X$ at position 5 may undergo easy nucleophilic substitution at $\mathbf{C}-5$. In addition to the route from $\mathbf{B}$ to $\mathbf{A}$, one could consider one more alternative strategy from $\mathbf{C}$ to $\mathbf{A}$.

\section{Results and Discussion}

\subsection{Synthesis of Isomers and Homologues of Beta-Nitro-6-Methylpyridin-2-One (1a-d)}

The simplest scheme for the synthesis of 3- and 5-nitro derivatives of 6-methylpyridin-2-one was the diazotation of 2-amino-3(5)-nitro-6-picolines, which, in turn, are available by nitration of commercial 2-amino-6-picoline to 2-nitramino-6-picoline (95\%) and its further acidic rearrangement (51\%) and steam distillation (leading to 39\% of 5-nitro- and 15\% of 3-nitropyridin-2-ones). By this way (Scheme 2) both isomers, namely 6-methyl-3-nitropyridin-2-one (1a, yield 32\% [11]) and 6-methyl-5-nitropyridin-2-one (1b, yield 25\% [12]), were obtained; the low yield at the last step may be due to high solubility of products in acetone for recrystallization.<smiles></smiles><smiles></smiles><smiles>CC(=O)CC(C)=O</smiles><smiles>Cc1cc(C)c([N+](=O)[O-])c(=O)[nH]1</smiles><smiles>Cc1cc(C)c(C#N)c(=O)[nH]1</smiles>

(i) $\mathrm{KNO}_{3}$ /oleum

(ii) $\mathrm{H}_{2} \mathrm{SO}_{4} . \Delta$<smiles>Cc1cc(=O)[nH]c(C)c1[N+](=O)[O-]</smiles>

Scheme 2. Synthesis of the parent homologues of beta-nitro-6-pyridin-2-ones.

In addition, two 4-methyl homologues of pyridones $\mathbf{1 a}, \mathbf{b}$ were described in literature. To prepare 4,6-dimethyl-3-nitropyridin-2-one (1c) we performed the cyclization of acetylacetone with nitroacetamide and obtained the target compound 1c with the yield 37\% [13]. For preparation of nitroacetamide we used the isonitroacetoacetic ester, which was dangerous for synthetic chemists due to ability to detonate above $100{ }^{\circ} \mathrm{C}$. (In addition, freshly isolated dry nitroacetamide was capable to self-ignition upon contact with air.) Finally, the synthesis of 4,6-dimethyl-5-nitropyridin-2-one (1d, yield 19\% [14]) was achieved in two steps by nitration of Guaresci pyridine (obtained with the yield $93 \%$ and nitrated with the yield $47 \%$ ) and consequent removal of the CN group in diluted sulfuric acid (low yield at this step may be due to solubility of product both in acid and in alkali used for neutralization).

\subsection{Attempts of Direct Phenacylation of Homologues of Beta-Nitropyridin-2-Ones}

Alkylation (and phenacylation) of pyridin-2-ones may occur either at $\mathrm{N}$ - or O-atoms [9]. Based on the literature data of reaction of phenacyl bromides with 4,6-dimethylpyridin-2-ones (bearing electron withdrawing group $\mathrm{CN}, \mathrm{CONH}_{2}, \mathrm{CO}_{2} \mathrm{R}$ at $\left.\mathrm{C}-5\right)[6,7,15-18]$ ) we expected that alkylation of sodium salts of 6-methyl-beta-nitropyridin-2-ones (1a-d) would also proceed at the nitrogen atom. As an additional argument, Na-salt of 5-nitropyridin-2-one also underwent $N$-phenacylation [19]. We believed that the resulting mixtures of $N$ - and $O$-phenacyl derivatives from $1 \mathbf{1}-\mathbf{d}$ could be chromatographically 
separated, since it is often mentioned in the literature that the chromatographic behavior of $\mathrm{N}$ - and O-isomers is different.

It turned out, however, that when trying to phenacylate the Na-salt of nitropyridones 1a-d, the reactions proceeded with an extremely low yield. As can be seen, a combination of factors (a sterically hindered nitrogen atom deactivated by a nitro group) prevents $\mathrm{N}$-alkylation. The result obtained completely excluded the opportunity to implement our planned strategy. In search of a possible solution to the problem, we drew attention to the other strategy described in the literature for the regioselective synthesis of pyridones with a phenacyl residue at the nitrogen atom using 2-methoxypyridines $[9,20,21]$. In this case, O-demethylation in the intermediate salt was apparently due to the attack of a rather weak nucleophile, the bromide ion. As a result, the methyl group acted as a protective group, and this method allowed selective and reliable preparation of $\mathrm{N}$-phenacyl derivatives. For our purposes, we should use 2-methoxy-beta-nitropyridines (with a kind of protection-a methoxy group, which not only prevents competitive O-alkylation but also acts as a donor residue that promotes $\mathrm{N}$-alkylation).

\subsection{Synthesis of Beta-Nitro-2-Methoxypyridine Homologues and Their Phenacylation}

An analysis of the literature showed that it is not a serious problem to convert the beta-nitropyridin-2-ones into 2-methoxypyridines with the intermediacy of 2-chloropyridines. The conversion of pyridin-2-ones to 2-chloropyridines proceeded with high yields upon boiling

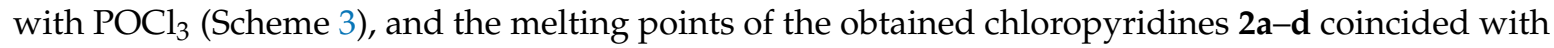
the published data (Table 1). The next stage - the replacement of $\mathrm{Cl}$ with a $\mathrm{MeO}$ group—was carried out by boiling with $\mathrm{MeONa}$ in methanol. The yields and melting points of the obtained substances $\mathbf{3 a}-\mathbf{d}$ are shown in Table 1.<smiles>[R]c1cc([N+](=O)[O-])c(OC)nc1C(C)(C)C(=O)Oc1cc([R])c([N+](=O)[O-])c(C)c1</smiles>

Scheme 3. Conversion of beta-nitropyridin-2-ones to 2-cloro- and 2-methoxy derivatives. 1-3: $\mathbf{a}, \mathbf{b} \mathrm{R}=$ $\mathrm{H} ; \mathbf{c}, \mathbf{d ~ R}=\mathrm{CH}_{3}$.

Table 1. Yields, $\mathrm{mp}$ and literature references for compounds $\mathbf{2} \mathbf{a}-\mathbf{d}$ and $\mathbf{3 a} \mathbf{a} \mathbf{d}$.

\begin{tabular}{ccccc}
\hline No & Yield, $\%$ & Mp & Mp, Lit & Reference \\
\hline 2a & 45 & 68 & $70-70.8$ & {$[22]$} \\
3a & 32 & 57 & $67-69$ & {$[23]$} \\
2b & 25 & $54-55$ & $57-58$ & {$[24]$} \\
3b & 36 & 64 & $64-65$ & {$[25]$} \\
2c & 64 & 47 & $47-48$ & {$[26]$} \\
3c & 90 & $104-105$ & 104 & {$[28]$} \\
2d & 85 & 54 & $54-55$ & {$[27]$} \\
3d & 92 & $59-60$ & 60 & {$[14]$} \\
\hline
\end{tabular}


After numerous attempts to phenacylate 2-methoxypyridines 3, we found the only acceptable method-melting of the starting reagents, Scheme 4. Such melting of reagents (in comparison with their boiling in acetonitrile) increased the yields 17 times, and they achieved 35\%. The structure of $N$-phenacyl derivatives clearly followed from the spectral data. The ${ }^{1} \mathrm{H}-\mathrm{NMR}$ spectra of phenacylpyridones $4 \mathbf{a}, \mathbf{b}$ contain the expected signals of the phenacyl residue and a fragment of nitropyridone. The final confirmation of the structure of the $N$-phenacylpyridone 4 a was obtained by X-ray diffraction, Figure 1. The yields for other methoxypyridines $(\mathbf{3 a}-\mathbf{c})$ were much lower.<smiles>COc1cc(C)c([N+](=O)[O-])c(C)n1</smiles><smiles>[R]C(=O)OCC(C)I</smiles>
1d fusion 4,5: a R $=4-\mathrm{ClC}_{6} \mathrm{H}_{4}$ $\mathrm{b} \mathrm{R}=4-\mathrm{BrC}_{6} \mathrm{H}_{4}$<smiles>[R]C(=O)Cn1c(C)c([N+](=O)[O-])c(C)cc1=O</smiles>

Scheme 4. Phenacylation of nitropyridones and consequent cyclization.

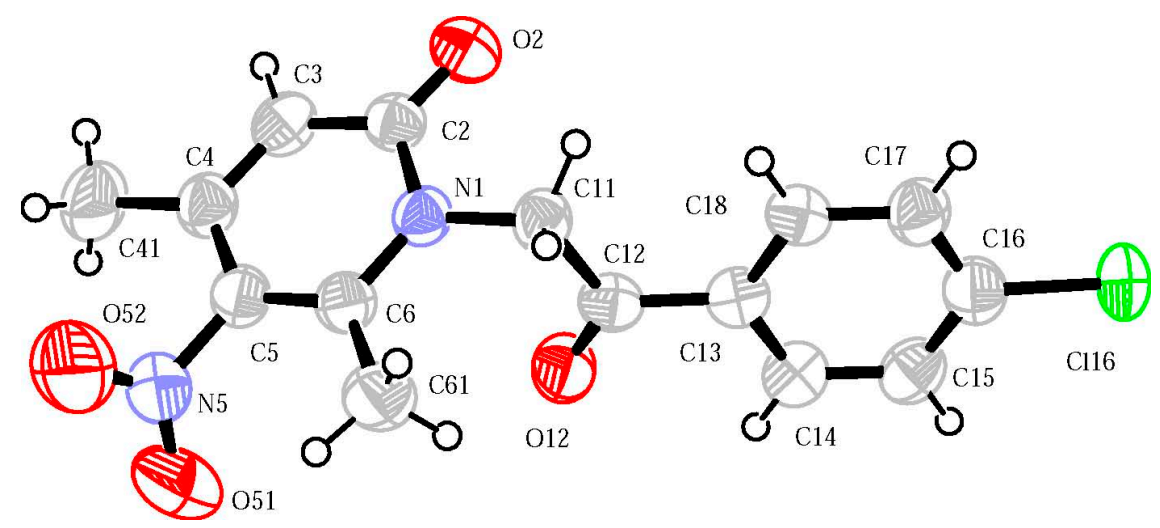

Figure 1. The general view of molecular structure of $4 \mathbf{a}$ in representation of atoms by displacement parameters ellipsoids $(\mathrm{p}=30 \%)$.

\subsection{Cyclocondensation of N-Phenacylpyridones under Basic Condition}

For studies of the cyclization of phenacylpyridones, we used compounds $\mathbf{4 a}, \mathbf{b}$ obtained in acceptable quantities (see Experimental section). In the solution of $\mathbf{4 a} \mathbf{a}, \mathbf{b}$ in $\mathrm{MeOH}$, an intense dark red color is observed. The neutralization of the reaction mixture allowed us to identify individual powdery 
compounds of dark red color. Their solutions turned black-green. The data of ${ }^{1} \mathrm{H}-$ and ${ }^{13} \mathrm{C}-\mathrm{NMR}$ spectra showed that both compounds are substituted indolizines 5a,b with the structure of 5-hydroxy tautomers, Scheme 4. This observation contradicted to the structure of 6-CN-5-hydroxy indolizines to which 5-oxo-3- $\mathrm{CH}_{2}$-type of tautomers was assigned [6,7]. In the ${ }^{1} \mathrm{H}-\mathrm{NMR}$ spectrum, we observed three singlets (in addition to multiplet of aryl residue and $\mathrm{CH}_{3}$ singlet). Two of them were from protons $\mathrm{H}-1$ and $\mathrm{H}-3$ of the pyrrole fragment, and the third one-at 4.4-5.4 ppm-was a singlet of the proton $\mathrm{H}-6$ of the pyridine fragment. The last peak was shifted to a high field due to the ortho-located hydroxy group, whose signal appeared as a broadened peak in the region of 3.1-3.4 ppm. The confirmation that in this case indolizine existed precisely in the hydroxy form was the appearance in the IR spectrum of the characteristic vibration frequency of the $\mathrm{OH}$ group at $3437 \mathrm{~cm}^{-1}$.

The reasons why 5-hydroxy (oxo) indolizines existed in the oxy or oxo form depended, obviously, on the nature of the additional acceptor substituent in the pyridine nucleus. In the case of 6-cyano derivatives, the tautomeric equilibrium was completely shifted towards the oxo form, while in the case of 8-nitroindolizins, the oxy form prevailed. These groups were likely to have different effects on the acidity of the 5-OH group and the basicity of the C-3 atom of the pyrrole moiety (onto which the proton of the hydroxyl group can migrate).

By analogy with 6-cyanoindolizinones [7], we expected that the action of phosphorus oxychloride on the corresponding nitroindolizinoles would lead to the replacement of 5-oxo/oxy-group with chlorine. It turned out, however, that when both hydroxyindolizines were heated with $\mathrm{POCl}_{3}$, complete resinification was observed. Probably the phenolic nature of the obtained indolizines somehow prevented the occurrence of such a transformation.

\subsection{Synthesis of 5-Substituted Indolizine via Oxazolopyridinium Salt}

As we have seen, it was possible to obtain intermediate compounds, representatives of a previously unknown class of 5-hydroxyindolizines, and their structure was very interesting. It turned out, however, that these compounds were unpromising for introduction of any other functions to position 5 (since they cannot be converted into 5-chloro derivatives). This can mean that it was completely impossible to vary the residue at position 5 in the series of 6(8)-nitroindolizines within the framework of our chosen strategy.

We were able to show that the precursors of 5-hydroxyindolizines, phenacylpyridones 4, were very promising synthons for producing 6 (8)-nitroindolizines with a substituent other than the hydroxy group in position 5. It is known that such phenacylpyridones can close two different cycles under the action of bases and acids. In the last case cyclodehydration may lead to closure of the oxazolium cycle. We found that, under the action of concentrated sulfuric acid, phenacylpyridone 4 a were smoothly cyclized to the corresponding oxazolopyridinium cation 6, isolated in the form of perchlorate, Scheme 5. In the ${ }^{1} \mathrm{H}-\mathrm{NMR}$ spectrum of the obtained salt, a singlet in low field appeared at $9.72 \mathrm{ppm}$, which corresponded to the proton of the newly formed oxazolium ring. The final proof of the structure of the obtained heterocycle 6 was obtained by X-ray diffraction, Figure $2 a$.

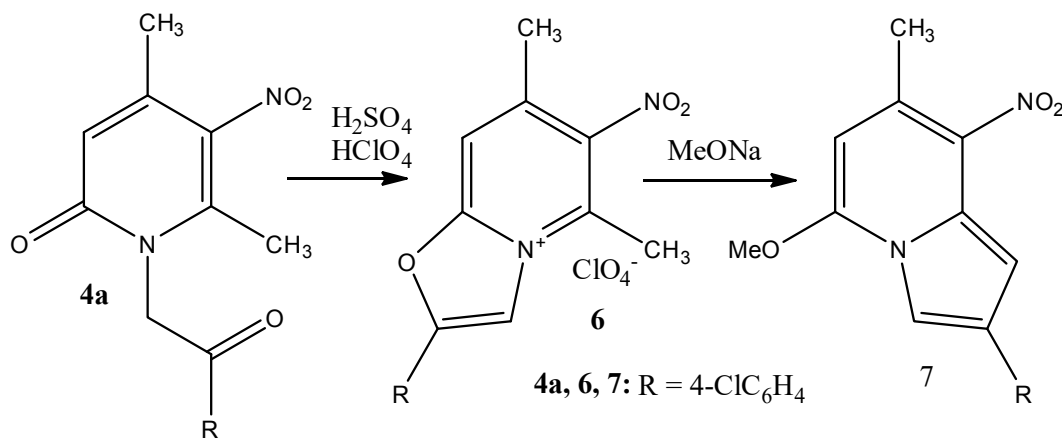

Scheme 5. Closure of oxazolium ring in N-phenacylpyridone and further recyclization. 
(a)

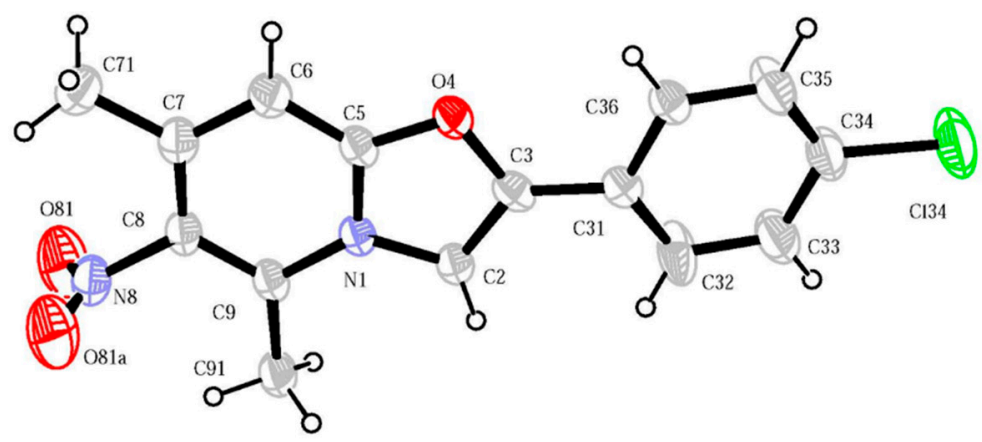

(b)

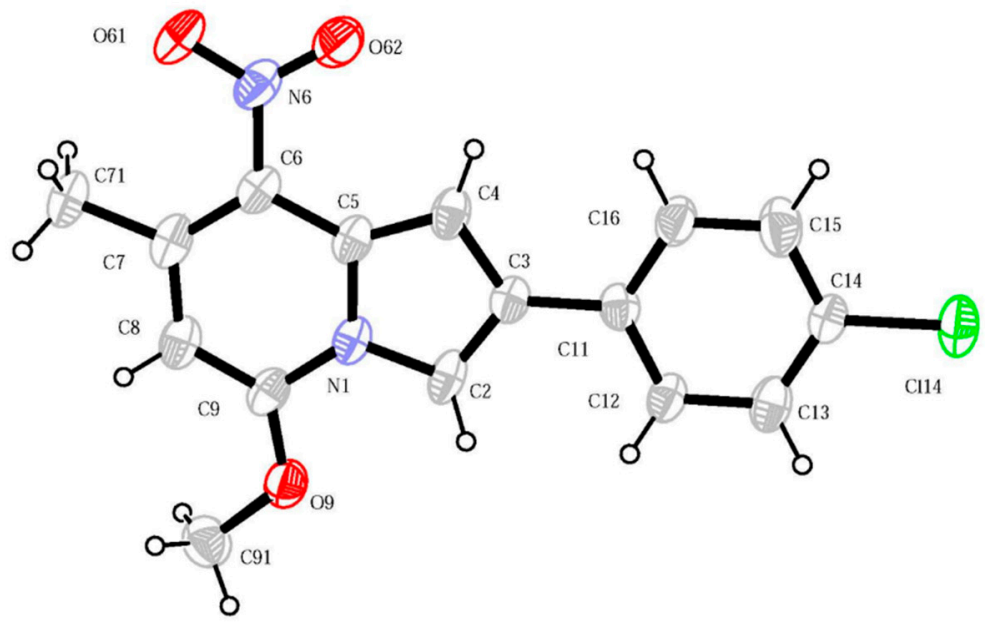

Figure 2. The general view of molecular structures of $\mathbf{6}(\mathbf{a})$ and 7 (b) in representation of atoms by displacement parameters ellipsoids $(\mathrm{p}=30 \%)$. A perchlorate anion for 6 and solvate acetone molecule for $\mathbf{7}$ are omitted for clarity.

The resulting compound 6 was capable of easily reacting with nucleophiles. It turned out that in the reaction with $\mathrm{MeONa}$, compound 6 underwent a rearrangement with the destruction of the oxazolium ring and the closure of a new pyrrole ring, forming 5-methoxy-8-nitroindolizine 7, Scheme 5 . The structure of the obtained compound 7 was unambiguously proved by the $\mathrm{X}$-ray diffraction method, Figure $2 b$. (In the lattice there is a solvent molecule-acetone.)

Interestingly, the obtained 5-methoxy-8-nitroindolizine 7 was isostructural to the 5-hydroxy-8-nitroindolizines $\mathbf{5 a}, \mathbf{b}$ obtained above. Comparing the electronic absorption spectra of these two isostructural (and pi-isoelectronic) systems, one can conclude that the structure of the bands was similar.

\section{Materials and Methods}

\subsection{General Information}

${ }^{1} \mathrm{H}-\mathrm{NMR}$ spectra were recorded on a Bruker AC 400 instrument (Bruker, Bremen, Germany, operating frequency $360 \mathrm{MHz}$ ), ${ }^{13} \mathrm{C}-\mathrm{NMR}$ spectra were recorded on a frequency of $100 \mathrm{MHz}$. Chemical shifts are measured on a $\delta$-scale and are given in parts per million; $J$ given in Hertz. The reaction progress was monitored by TLC on Silufol UV-254 plates (Merck KGaA, Darmstadt, Germany), and the TLC manifestation was carried out by UV radiation (wavelengths of 254 and $365 \mathrm{~nm}$ ), iodine vapor, oxidation in a sulfuric aqueous solution of $\mathrm{KMnO}_{4}$, Ehrlich reagent or ninhydrin. Chromatographic separation was performed on columns or glass plates using silica gel with a particle size of 40-60 $\mu \mathrm{m}$ (Merck, KGaA, Darmstadt, Germany). Reagents from Acros (Fisher Scientific, Leicestershire, UK), Merck (Merck KGaA, Darmstadt, Germany) and Aldrich (Sigma-Aldrich Company 
Ltd., Dorset, UK) were used as starting materials for the syntheses. They were introduced into the reactions without additional purification. Elementary analysis data for new compounds are given in Table 2.

Table 2. Elementary analysis data for all new compounds.

\begin{tabular}{|c|c|c|c|c|c|c|c|}
\hline \multirow{2}{*}{ Compound (No.) } & \multirow{2}{*}{ Formula } & \multicolumn{3}{|c|}{ Calculated } & \multicolumn{3}{|c|}{ Found } \\
\hline & & $\mathrm{C}$ & $\mathbf{H}$ & $\mathbf{N}$ & $\mathrm{C}$ & $\mathbf{H}$ & $\mathbf{N}$ \\
\hline $\mathrm{N}$-(p-chlorophenacyl)-4,6-dimethyl-5-nitropyridin-2-one (4a) & $\mathrm{C}_{15} \mathrm{H}_{13} \mathrm{ClN}_{2} \mathrm{O}_{4}$ & 56.17 & 4.09 & 8.73 & 55.82 & 4.13 & 8.68 \\
\hline 2-p-chlorophenyl-5-hydroxy-7-methyl-8-nitroindolizine (5a) & $\mathrm{C}_{15} \mathrm{H}_{11} \mathrm{ClN}_{2} \mathrm{O}_{3}$ & 59.52 & 3.66 & 9.25 & 59.13 & 3.71 & 9.19 \\
\hline 2-p-Bromophenyl-7-methyl-8-nitro-5-hydroxyindolizine (5b) & $\mathrm{C}_{15} \mathrm{H}_{11} \mathrm{BrN}_{2} \mathrm{O}_{3}$ & 51.90 & 3.19 & 8.07 & 51.51 & 3.25 & 8.01 \\
\hline
\end{tabular}

${ }^{*}$ means ionic compound.

\subsection{Synthesis}

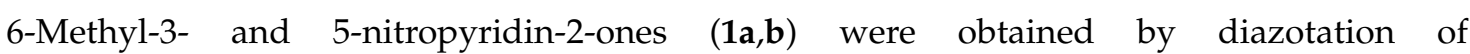
2-amino-3(5)-nitro-6-picolines [11,12]. 4,6-Dimethyl-3-nitropyridin-2-one (1c) obtained by cyclization of acetylacetone with nitroacetamide [13]. 4,6-Dimethyl-5-nitropyridin-2-one (1d) was obtained in two steps by nitration of Guaresci pyridine and further hydrolysis [14].

Studying of phenacylation of sodium salt 4,6-dimethyl-5-nitropyridin-2-one (1d). In methanol. To a solution of $0.483 \mathrm{~g}(0.021 \mathrm{~mol})$ of sodium metal in $100 \mathrm{~mL}$ of absolute methanol, $3.36 \mathrm{~g}(0.02 \mathrm{~mol}) \mathrm{of}$ nitropyridone $1 \mathrm{~d}$ and $4.9 \mathrm{~g}(0.021 \mathrm{~mol})$ of p-chlorophenacyl bromide are added with vigorous stirring. The mixture was stirred for $12 \mathrm{~h}$ at $55-60^{\circ} \mathrm{C}$ and controlled by TLC. Only traces of product could be observed. In benzene/xylene. To a benzene suspension of $0.5 \mathrm{~g}$ ( $2.9 \mathrm{mmol})$ sodium salt of pyridone $1 d 0.8 \mathrm{~g}$ ( $35 \mathrm{mmol}$ ) of p-bromophenacyl bromide was added. After $60 \mathrm{~h}$ at room temperature TLC monitoring showed the presence of only starting materials. The solvent was evaporated and the mixture was dissolved in o-xylene and boiled for another $6 \mathrm{~h}$. TLC control showed the presence of only traces of products.

Conversion of pyridin-2-ones $(\mathbf{1} \mathbf{a}-\mathbf{d})$ to 2 -chloropyridines (2a-d). The mixture of 0.036 mol of nitropyridone-2 (1a-d), $4 \mathrm{~mL}$ of $\mathrm{POCl}_{3}$ and $0.036 \mathrm{~mol}$ of $\mathrm{PCl}_{5}$ was maintained at $120{ }^{\circ} \mathrm{C}$ for $4 \mathrm{~h}$. The mixture was left at $120^{\circ} \mathrm{C}$ in a Wood alloy for $1.5 \mathrm{~h}$. The mixture was cooled to RT, poured into excess of ice water and the brown precipitate was filtered off, dried and recrystallized from hexane. The yields, m.p. of products $\mathbf{2} \mathbf{a}-\mathbf{d}$ and literature references are given in Table 2.

Conversion of 2-chloropyridines (2a-d) to 2-methoxypyridines (3a-d). To a solution of $\mathrm{MeONa}$ (obtained by dissolving $0.388 \mathrm{~g}(0.017 \mathrm{~mol})$ of sodium metal in $15 \mathrm{~mL}$ of absolute $\mathrm{MeOH}) 0.016 \mathrm{~mol}$ 2-chloropyridine $\mathbf{2 a}-\mathbf{d}$ was added. The mixture was boiled for $4 \mathrm{~h}$, the precipitated $\mathrm{NaCl}$ was filtered off, the filtrate was evaporated and the residue was chromatographed on a column $\left(\mathrm{SiO}_{2}\right.$, chloroform). The yields, m.p. of products $\mathbf{3 a - d}$ and literature references are given in Table 1.

$N$-(p-chlorophenacyl)-4,6-dimethyl-5-nitropyridin-2-one (4a). A mixture of $1.3 \mathrm{~g}(0.007 \mathrm{~mol})$ of methoxypyridine $3 \mathbf{e}$ and $1.75 \mathrm{~g}(0.007 \mathrm{~mol})$ of $\mathrm{p}$-chlorophenacyl bromide was dissolved in $10 \mathrm{~mL}$ of acetonitrile and the solution was boiled for $30 \mathrm{~h}$. The solvent was evaporated in vacuo. The resulting mixture was kept for $17 \mathrm{~h}$ at $100^{\circ} \mathrm{C}$ and $15 \mathrm{~h}$ at $120^{\circ} \mathrm{C}$, cooled to room temperature and chromatographed on a column $\left(\mathrm{SiO}_{2}\right.$, chloroform). Product $4 \mathrm{a}(0.14 \mathrm{~g})$ was obtained. Yield 6\%; m.p. $190-191{ }^{\circ} \mathrm{C} .{ }^{1} \mathrm{H}-\mathrm{NMR}$ Spectrum (DMSO-d $\left.)_{6}\right): 8.10(2 \mathrm{H}, \mathrm{m}, \mathrm{Ar}) ; 7.57(2 \mathrm{H}, \mathrm{m}, \mathrm{Ar}) ; 6.30(1 \mathrm{H}, \mathrm{s}, 3-\mathrm{H}) ; 5.65\left(2 \mathrm{H}, \mathrm{s}, \mathrm{CH}_{2}\right) ; 2.30(3 \mathrm{H}, \mathrm{s}$, 6- $\left.\mathrm{CH}_{3}\right) ; 2.22\left(3 \mathrm{H}, \mathrm{s}, 4-\mathrm{CH}_{3}\right)$. The molecular structure is shown in Figure 1 [28].

$N$-(p-bromophenacyl)-4,6-dimethyl-5-nitropyridin-2-one (4b). Obtained in a similar manner from methoxypyridine 3d and p-bromophenacyl bromide. Yield 8\%, m.p. $192{ }^{\circ} \mathrm{C} .{ }^{1} \mathrm{H}-\mathrm{NMR}$ Spectrum 
$\left(\mathrm{CDCl}_{3}\right): 7.92(2 \mathrm{H}, \mathrm{m}, \mathrm{Ar}) ; 7.78(2 \mathrm{H}, \mathrm{m}, \mathrm{Ar}) ; 6.94(1 \mathrm{H}, \mathrm{s}, 3-\mathrm{H}) ; 5.74\left(2 \mathrm{H}, \mathrm{s}, \mathrm{CH}_{2}\right) ; 2.30\left(3 \mathrm{H}, \mathrm{s}, 6(4)-\mathrm{CH}_{3}\right)$; $2.25\left(3 \mathrm{H}, \mathrm{s}, 4(6)-\mathrm{CH}_{3}\right)$.

Phenacylation of methoxypyridine 3d: synthesis optimization without use of a solvent.

(1) The reaction of $\mathbf{3 d}$ with p-chlorophenacyl bromides was carried out in a sealed glass ampoule, the reaction mass was heated in an oven for $25 \mathrm{~h}$ at temperature of $120-150{ }^{\circ} \mathrm{C}$. TLC analysis in pure chloroform showed the presence of the desired products. After chromatography, $0.378 \mathrm{~g}$ of a pure yellow substance, identical in TLC and m.p. with the N-isomer 4a. Yield $\sim 10 \%$.

(2) The substances were placed in a $50 \mathrm{~mL}$ flask equipped with a reflux condenser. The mixture was kept at $120^{\circ} \mathrm{C}$ for $7 \mathrm{~h}$ in a Wood alloy. After $5 \mathrm{~h}$ of boiling, the yellow liquid began to accumulate on the walls of the flask and flowed down. TLC analysis showed that it is phenacyl bromide. Then, after the cessation of gas formation, the temperature was raised to $200{ }^{\circ} \mathrm{C}$ (continued gas formation), and the mixture was kept at this temperature for another $3 \mathrm{~h}$. The reaction mixture was applied to silica gel and chromatographed with $\mathrm{CHCl}_{3}$, then $\mathrm{CHCl}_{3}$-EtOH. Recrystallized from acetone. The yield of $\mathrm{N}$-isomer 4 a was $15 \%$.

(3) $4 \mathrm{~g}$ of methoxypyridine $\mathbf{3 d}$ and a twofold excess of phenacyl bromide were taken. The substances are placed in a $50 \mathrm{~mL}$ flask equipped with a reflux condenser. The mixture was heated in a Wood alloy at $125^{\circ} \mathrm{C}$ for $20 \mathrm{~h}$. After this, the mixture was poured into a large amount of boiling petroleum ether and the precipitate was filtered off. A petroleum extract containing pure starting materials was reacted back. The precipitate was purified from the crude oil by chromatography, eluting with chloroform. The yield of the target product 4 a was $35 \%$.

Synthesis of 5-hydroxy-8-nitroindolizines 5a,b (General methodology). A total of $0.6 \mathrm{~g}$ of phenacylpyridone $4 \mathrm{a}(1.6 \mathrm{mmol})$ was dissolved in $100 \mathrm{~mL}$ of $\mathrm{MeOH}$. The calculated amount of $\mathrm{Na}(38 \mathrm{mg}$ ) was dissolved in $50 \mathrm{~mL}$ of $\mathrm{MeOH}$. A solution of MeONa was added with stirring to a solution of phenacylpyridone. The solution turned raspberry colored. In $30 \mathrm{~min}$ after the start of the reaction the calculated amount of HOAc was added to neutralize MeONa. The reaction mixture was diluted with diethyl ether, and the product and NaOAc precipitated. The solvent was distilled off on a rotary evaporator, the mixture was dissolved in a minimum amount of acetone and filtered from NaOAc. The solution was evaporated giving a brick-red substance, 2-p-chlorophenyl-5-hydroxy-7-methyl-8-nitroindolizine (5a). Yield 92\%. m.p. > $250{ }^{\circ} \mathrm{C}$ (decomp.). ${ }^{1} \mathrm{H}-\mathrm{NMR}$ Spectrum (CD $\left.\mathrm{OD}\right): 7.80$ (1H, m, 3-H); 7.72 (2H, m, Ar); 7.47 (2H, m, Ar); 7.29 (1H, m, 1-H); $5.37(1 \mathrm{H}, \mathrm{s}, 6-\mathrm{H}) ; 3.40(1 \mathrm{H}$, br s, $\mathrm{OH}) ; 2.57\left(3 \mathrm{H}, \mathrm{s}, \mathrm{CH}_{3}\right)$.

2-p-Bromophenyl-7-methyl-8-nitro-5-hydroxyindolizine (5b). Yield 90\%, m.p. > $250{ }^{\circ} \mathrm{C}$ (decomp.). ${ }^{1} \mathrm{H}-\mathrm{NMR}$ Spectrum $\left(\mathrm{CDCl}_{3}\right): 7.34(1 \mathrm{H}, \mathrm{m}, 3-\mathrm{H}) ; 7.17(2 \mathrm{H}, \mathrm{m}, \mathrm{Ar}) ; 7.08(2 \mathrm{H}, \mathrm{m}, \mathrm{Ar}) ; 6.82$ (1H, m, 1-H); $4.37(1 \mathrm{H}, \mathrm{s}, 6-\mathrm{H}) ; 3.10(1 \mathrm{H}$, br s, $\mathrm{OH}) ; 2.13\left(3 \mathrm{H}, \mathrm{s}, \mathrm{CH}_{3}\right)$.

2-(p-Chlorophenyl)-5,7-dimethyl-6-nitrooxazolo [3,2-a]pyridinium perchlorate (6). A mixture of $0.1 \mathrm{~g}$ $(0.3 \mathrm{mmol})$ of phenacylpyridone $5 \mathbf{a}$ and $1 \mathrm{~mL}$ of concentrated sulfuric acid was maintained at $22{ }^{\circ} \mathrm{C}$ for $18 \mathrm{~h}$. Then, $0.2 \mathrm{~mL}$ of $70 \% \mathrm{HCiO}_{4}$ was added to the mixture, incubated for $1 \mathrm{~h}$, poured into $100 \mathrm{~mL}$ of absolute ether and the precipitate formed was filtered off. The yield of perchlorate is $92 \%$; m.p. 295-297 ${ }^{\circ} \mathrm{C}$ (decomp.). ${ }^{1} \mathrm{H}-\mathrm{NMR}$ Spectrum (DMSO-d 6$): 9.72(1 \mathrm{H}, \mathrm{s}, 3-\mathrm{H}) ; 8.60(1 \mathrm{H}, \mathrm{s}, 8-\mathrm{H}) ; 8.07$ (2H, m, $\mathrm{Ar}) ; 7.82(2 \mathrm{H}, \mathrm{m}, \mathrm{Ar}) ; 2.89\left(3 \mathrm{H}, \mathrm{s}, 5-\mathrm{CH}_{3}\right) ; 2.67\left(3 \mathrm{H}, \mathrm{s}, 7-\mathrm{CH}_{3}\right) .{ }^{13} \mathrm{C}-\mathrm{NMR}\left(\mathrm{DMSO}-d_{6}\right): 15.4 ; 18.5 ; 110.6$; $112.1 ; 122.6 ; 127.5 ; 130.1 ; 137.1 ; 137.8 ; 144.8 ; 145.8 ; 152.2 ; 152.4$. X-Ray data see Figure 2a. The molecular structure is seen in Figure 2a (perchlorate anion is omitted for clarity) [29].

2-(p-Chlorophenyl)-5-methoxy-7-methyl-8-nitroindolizine (7). A total of $200 \mathrm{mg}(0.49 \mathrm{mmol})$ of oxazolopyridinium salt 6 was added to a solution of $10 \mathrm{mg}$ of sodium in $10 \mathrm{~mL}$ of methanol. The mixture was kept for 1 day at $22{ }^{\circ} \mathrm{C}$ and the precipitate formed was filtered off. Product $7(110 \mathrm{mg})$ was obtained. Yield 73\%, m.p. $175-176{ }^{\circ} \mathrm{C} .{ }^{1} \mathrm{H}-\mathrm{NMR}$ Spectrum: 7.50 (6H, m, Ar); $5.73(1 \mathrm{H}, \mathrm{s}, 6-\mathrm{H}) ; 4.22$ $\left(3 \mathrm{H}, \mathrm{s}, \mathrm{O}-\mathrm{CH}_{3}\right) ; 2.69\left(3 \mathrm{H}, \mathrm{s}, \mathrm{CH}_{3}\right)$. The molecular structure see Figure $2 \mathrm{~b}$ (solvate acetone molecule is omitted for clarity) [30]. 


\subsection{X-ray Diffraction Studies}

For single crystals of compounds $4 \mathbf{a}$ and $\mathbf{6}$, the experimental intensities of diffraction reflections were obtained on a CAD- 4 diffractometer $(\lambda \mathrm{Cu} K \alpha$ radiation, graphite monochromator, $\omega$ scanning at room temperature, Enraf-Nonius, Delft, Netherlands), for compound 7 on a CAD-4 diffractometer ( $\lambda$ Mo $\mathrm{K} \alpha$ radiation, graphite monochromator, $\omega$-scan, at room temperature). All subsequent calculations were performed as part of the SHELX software package [31]. The crystallographic data for the studied structures were deposited in the Cambridge Structural Database with the numbers CCDC 1986879 for 4a, CCDC 1986629 for 6, CCDC 1984804 for 7.

\section{Conclusions}

In conclusion, the reaction between the derivatives of 6-methyl-beta-nitropyridin-2-one (1a-d) and phenacyl bromides did not occur for steric and electronic reasons. However, 4,6-dimethyl-2-methoxy-5-nitropyridine $3 \mathbf{d}$ on fusion with bromoketones could be $\mathrm{N}$-phenacylated. Its $N$-phenacyl derivatives $\mathbf{4 a}, \mathbf{b}$ under the action of base gave 5 -hydroxy-8-nitroindolizines $(\mathbf{5} \mathbf{a}, \mathbf{b})$ and under acidic conditions gave 5-methyl-6-nitrooxazole[3,2-a]pyridinium salt 6, which underwent recycization with MeONa to 5-methoxy-8-nitroindolizine 7.

Author Contributions: E.V.B. formulated the goals, managed performance of all experimental work and wrote the paper. V.B.R. performed X-ray analysis. All authors have read and agreed to the published version of the manuscript.

Funding: This work was supported by RFBR grant No19-53-53009 GFEN_a.

Acknowledgments: We thank R. Lukov for help in experimental work. The authors are grateful to Thermo Fisher Scientific Inc., Analitika (Moscow), and personally to A.A. Makarov for providing the mass spectrometric equipment used in this work.

Conflicts of Interest: The authors declare no conflicts of interest.

\section{References}

1. Flitsch, W. Pyrroles with fused six-membered heterocyclic rings: A-fused. In Comprehensive Heterocyclic Chemistry; Katritzky, A., Rees, C.W., Eds.; Pergamon Press: Oxford, UK, 1984; Volume 4, pp. 443-496.

2. Renard, M.; Gubin, J. Metallation of 2-Phenylindolizine. Tetrahedron Lett. 1992, 33, 4433-4434. [CrossRef]

3. Kuznetsov, A.G.; Bush, A.A.; Rybakov, V.B.; Babaev, E.V. An Improved Synthesis of Some 5-Substituted Indolizines Using Regiospecific Lithiation. Molecules 2005, 10, 1074-1083. [CrossRef] [PubMed]

4. Rzhevskii, S.A.; Rybakov, V.B.; Khrustalev, V.N.; Babaev, E.V. Reactions of 5-Indolizyl Lithium Compounds with Some Bielectrophiles. Molecules 2017, 22, 661. [CrossRef] [PubMed]

5. Kost, A.N.; Sagitullin, R.S.; Gromov, S.P. Nucleophilic amination and recyclization of the indolizine nucleus. Heterocycles 1977, 7, 997-1001.

6. Gevald, K.; Jansch, H.J. 3-Amino-furo[2.3-b]pyridine. J. Prakt. Chem. 1976, 318, 313-320.

7. Babaev, E.V.; Vasilevich, N.I.; Ivushkina, A.S. Efficient synthesis of 5-substituted 2-aryl-6-cyanoindolizines via nucleophilic substitution reactions. Beilstein J. Org. Chem. 2005, 1, 9-11. [CrossRef]

8. Babaev, E.V. Fused Munchnones in Recyclization Tandems. J. Heterocycl. Chem. 2000, 37, 519-526. [CrossRef]

9. Babaev, E.V.; Alifanov, V.L.; Efimov, A.V. Oxazolo[3,2-a]pyridinium and Oxazolo[3,2-a]pyrimidinium Salts in Organic Synthesis. Russ. Chemical Bull. 2008, 57, 845-862. [CrossRef]

10. Bradsher, C.K.; Zinn, M.F. Oxazolo[3,2-a] pyridinium salts. J. Heterocycl. Chem. 1967, 4, 66-70. [CrossRef]

11. Krasnaya, Z.A.; Stytsenko, T.S.; Prokof'ev, E.P.; Yakovlev, I.P.; Kucherov, V.F. Reaction of enaminocarbonyl compounds with nitroacetic ester. Bull. Acad. Sci. USSR 1974, 23, 809-816. [CrossRef]

12. Goerlitzer, K.; Wilpert, C.; Ruebsamen-Waigmann, H.; Suhartono, H.; Wang, L.; Immelmann, A. Pyrido[3,2-e][1,4] diazepine-Synthese und Prüfung auf Anti-HIV-1-Wirkung. Arch. Pharm. 1995, 328, 247-256. [CrossRef] [PubMed]

13. Kislyi, V.P.; Shestopalov, A.M.; Kagramanov, N.D.; Semenov, V.V. Synthesis of 3-nitropyrid-2(1H)-ones from C-nitroacetamide and 1,3-dicarbonyl compounds. Russ. Chem. Bull. 1997, 46, 539-542. [CrossRef] 
14. Mariella, R.P.; Callahan, J.J.; Jibril, A.O. Some novel color reactions of some pyridine derivatives. J. Org. Chem. 1955, 20, 1721-1728. [CrossRef]

15. Rybakov, V.B.; Babaev, E.V.; Paronikyan, E.G. X-Ray Mapping in Heterocyclic Design: 18. X-Ray Diffraction Study of a Series of Derivatives of 3-Cyanopyridine-2-one with Annelated Heptane and Octane Cycles. Crystallogr. Rep. 2017, 62, 219-231. [CrossRef]

16. Rybakov, V.B.; Babaev, E.V. Transformations of Substituted Oxazolo[3,2-a]Pyridines to 5,6-Disubstituted Indolizines: Synthesis And X-ray Structural Mapping. Chem. Heterocycl. Comp. 2014, 50, 225-236. [CrossRef]

17. Okul', E.M.; Rybakov, V.B.; Babaev, E.V. The structure of products of phenacylation and subsequent (re)cyclizations of 3-acetyl-4,6-dimethylpyridin-2(1H)-one according to X-ray structural analysis. Chem. Heterocycl. Comp. 2017, 53, 997-1002. [CrossRef]

18. Feklicheva, E.M.; Rybakov, V.B.; Babaev, E.V.; Oficerov, E.N. Physical-chemical investigations of transformations in the series of 2,4-dimethyl-6-oxo-1,6-dihydropyridine-3-carboxanmide. Part 1. Synthesis and X-ray study of derivatives of 2,4-dimethyl-6-oxo-1,6-dihydropyridine-3-carboxanmide. Butlerov Communications 2019, 60, 1-23.

19. Bush, A.A.; Babaev, E.V. Synthesis of 6-Nitroderivatives of Oxazolo[3,2-a]pyridines and their Reactions with Nucleophiles. Molecules 2003, 8, 460-466. [CrossRef]

20. Babaev, E.V.; Efimov, A.V.; Maiboroda, D.A. Hetarenes with a nitrogen bridging atom. 1. Phenacylation of 2-substituted 6-methylpyridines. Chem. Heterocycl. Comp. 1995, 31, 962-968. [CrossRef]

21. Babaev, E.V.; Tsisevich, A.A.; Al'bov, D.V.; Rybakov, V.B.; Aslanov, L.A. Heterocycles with a bridgehead nitrogen atom. Part 16. Assembly of a peri-fused system from an angular tricycle by recyclization of an oxazole ring into pyrrole one. Russ. Chem. Bull. 2005, 54, 259-261. [CrossRef]

22. Parker, E.D.; Shive, W. Substituted 2-Picolines Derived from 6-Amino-2-picoline. J. Amer. Chem. Soc. 1947, 69, 63-67. [CrossRef]

23. Remennikov, G.Y.; Kurilenko, L.K.; Boldyrev, I.V.; Cherkasov, V.M. The recyclization of 5-nitropyrimidine and its methoxy derivatives upon reaction with the acetylacetone carbanion. Chem. Heterocycl. Comp. 1987, 23, 422-425. [CrossRef]

24. Frydman, B.; Reil, S.J.; Boned, J.; Rapoport, H. Synthesis of substituted 4- and 6-azaindoles. J. Org. Chem. 1968, 33, 3762-3766. [CrossRef]

25. Baumgarten, H.E.; Su, H.C.-F. Synthesis of 3- and 5-nitro-2-picoline and derivatives. J. Amer. Chem. Soc. 1952, 74, 3828-3830. [CrossRef]

26. Sawanishi, H.; Tajima, K.; Tsuchiya, T. Studies on Diazepines. XXVIII. Syntheses of 5H-1,3-Diazepines and 2H-1,4-Diazepines from 3-Azidopyridines. Chem. Pharm. Bull. 1987, 35, 4101-4109. [CrossRef]

27. Kislyi, V.P.; Semenov, V.V. Investigation of the regioselectivity of alkylation of 3-nitropyridine-2(1H)-ones. Russ. Chem. Bull. 2001, 50, 460-463. [CrossRef]

28. Babaev, E.V.; Rybakov, V.B. CCDC 1986879. Experimental Crystal Structure Determination. 2020. Available online: https://doi.org/10.5517/ccdc.csd.cc24phw7 (accessed on 27 February 2020).

29. Babaev, E.V.; Rybakov, V.B. CCDC 1986629. Experimental Crystal Structure Determination. 2020. Available online: https://doi.org/10.5517/ccdc.csd.cc24p7tx (accessed on 27 February 2020).

30. Babaev, E.V.; Rybakov, V.B. CCDC 1984804. Experimental Crystal Structure Determination. 2020. Available online: https://doi.org/10.5517/ccdc.csd.cc24mby2 (accessed on 18 February 2020).

31. Sheldrick, G.M. Crystal structure refinement with SHELX. Acta Cryst. 2015, C71, 3-8. [CrossRef]

Sample Availability: Samples of the compounds 6 and 7 are available from the authors. 